\title{
Observation and Parameterization of Ablation at the Base of Ronne Ice Shelf, Antarctica
}

\author{
Adrian Jenkins, Keith W. Nicholls, and Hugh F. J. CorR \\ British Antarctic Survey, Natural Environment Research Council, Cambridge, United Kingdom
}

(Manuscript received 21 July 2009, in final form 30 April 2010)

\begin{abstract}
Parameterizations of turbulent transfer through the oceanic boundary layer beneath an ice shelf are tested using direct measurements of basal ablation. Observations were made in the southwestern part of Ronne Ice Shelf, about $500 \mathrm{~km}$ from open water. The mean basal ablation rate was measured over a month-long and a year-long period using phase-sensitive radar to record the thinning of the ice shelf. Ocean temperatures were observed within about $25 \mathrm{~m}$ of the ice shelf base over the period of the radar observations, while the tidally dominated ocean currents were estimated from tidal analysis of collocated current observations from an earlier period. Ablation rates derived using these ocean data and a number of bulk parameterizations of turbulent transfer within the boundary layer are compared with the direct measurements. The ablation rates derived using a parameterization that explicitly includes the impact of ocean currents on the turbulent transfer of heat and salt match the observations to within $40 \%$; with suitable tuning of the drag coefficient, the mismatch can be reduced below the level of the observational errors. Equally good agreement can be obtained with two slightly simpler, current-dependent parameterizations that use constant turbulent transfer coefficients, and the optimal values for the coefficients at this particular location on Ronne Ice Shelf are given.
\end{abstract}

\section{Introduction}

Ice shelves are floating extensions that form at the margins of ice sheets where the ice is not thick enough to maintain contact with a bed that lies below sea level. Beneath the ice shelves is a unique oceanic environment, isolated from the atmosphere by ice that typically ranges from 100 to $2000 \mathrm{~m}$ thick and forced to a large extent by the phase changes that occur at the ice shelf base. The processes that occur at the interface between ice shelf and ocean constitute the only direct interaction between the earth's ice sheets and oceans and have important implications for both. Modification of water masses beneath the Antarctic ice shelves is one step in the formation of the densest varieties of Antarctic Bottom Water (e.g., Nicholls et al. 2009), the descent of which to the ocean abyss represents the deepest limb of the global meridional overturning circulation. Mass exchange at the ice shelf base is the most important driver of changes in ice shelf thickness, and these, through the

Corresponding author address: Adrian Jenkins, British Antarctic Survey, High Cross, Madingley Road, Cambridge CB3 0ET, United Kingdom.

E-mail: ajen@bas.ac.uk dynamic coupling between ice sheet and ice shelf (Schoof 2007), affect the discharge of grounded ice to the ocean and hence global eustatic sea level.

The interaction between ice shelves and the ocean is thus a key element of the climate system; however, the processes are immensely challenging to observe. A number of access holes have been drilled through ice shelves (e.g., Nicholls et al. 2009), but the limited availability of slim-line instrumentation that can be deployed through a typically $30 \mathrm{~cm}$ wide opening has restricted the types of measurements that have been made in the water column beneath. Crucially, there have been, as yet, no observations of turbulent transfer in the oceanic boundary layer at the ice shelf base. Turbulent mixing is the critical process by which the sensible heat content and motion of the water is translated into the phase changes that control both the mass balance of the ice shelf and the buoyancy forcing on the subice ocean circulation.

Models of the circulation beneath ice shelves thus tend to draw on knowledge gained from observations of the turbulent boundary layer beneath sea ice so as to parameterize the thermodynamic interaction between ice and ocean (Holland and Jenkins 1999). Also technically challenging to make, observations beneath sea ice are at least free of the geometric constraints imposed 
on the instrumentation that can be deployed through a $30-\mathrm{cm}$ borehole, and the literature on the turbulent oceanic boundary layer beneath sea ice is comparatively extensive (e.g., McPhee 2008). Although this knowledge should, in principle, be transferrable to the subice shelf boundary layer, there are subtle differences in the nature of the ice-ocean interface and dynamics of the boundary layer. The ice shelf base will be mostly free of the large-scale irregularities associated with ridges and leads in sea ice, although limited areas are subject to rifting and could feature other complexities that might be unsuspected from observations of the upper surface morphology (Nicholls et al. 2006). Also, the current shear that is the main source of turbulent kinetic energy near the ice shelf base is generated by the interaction of the far-field flow with a solid, motionless boundary, more analogous to the benthic than to the surface boundary layer, while the large-scale slope of the ice shelf base means that the buoyancy-driven flow of the boundary layer itself can become a major contributor to the current shear.

In this paper, we analyze a unique set of observations that enables us, for the first time, to test the various parameterizations of turbulent transfer through the iceocean boundary layer that have been used in models of ocean circulation beneath ice shelves. The observations were made on the Ronne Ice Shelf, which together with the Filchner Ice Shelf comprises volumetrically the largest contiguous body of floating ice on the planet. The ice at the measurement site, located $500 \mathrm{~km}$ from the ice front (Fig. 1), is about $820 \mathrm{~m}$ thick. In early 1996, an instrument string was installed beneath the ice shelf (Nicholls et al. 1997) and data were logged until late 2002. The data initially included conductivity, temperature, and currents, but the number of time series gradually diminished as instruments and batteries expired. Neither the response time of the instruments nor their spatial arrangement was adequate to resolve turbulent time and length scales and, therefore, the heat and salt fluxes to the ice base. However, between early January and mid-December 2001 a series of measurements were made to determine the basal ablation rate of the ice shelf at the same site. When combined with data from thermistors frozen into the ice near the ice shelf base, these observations give us all of the information required to estimate the net scalar fluxes that result from turbulent transfer through the oceanic boundary layer. The technique used to measure the basal ablation is described in detail by Corr et al. (2002) and Jenkins et al. (2006). At its heart is the precise measurement of ice thickness changes by phase-sensitive radar.

We begin by reviewing the theory of turbulent transfer through the ice-ocean boundary layer and by summarizing

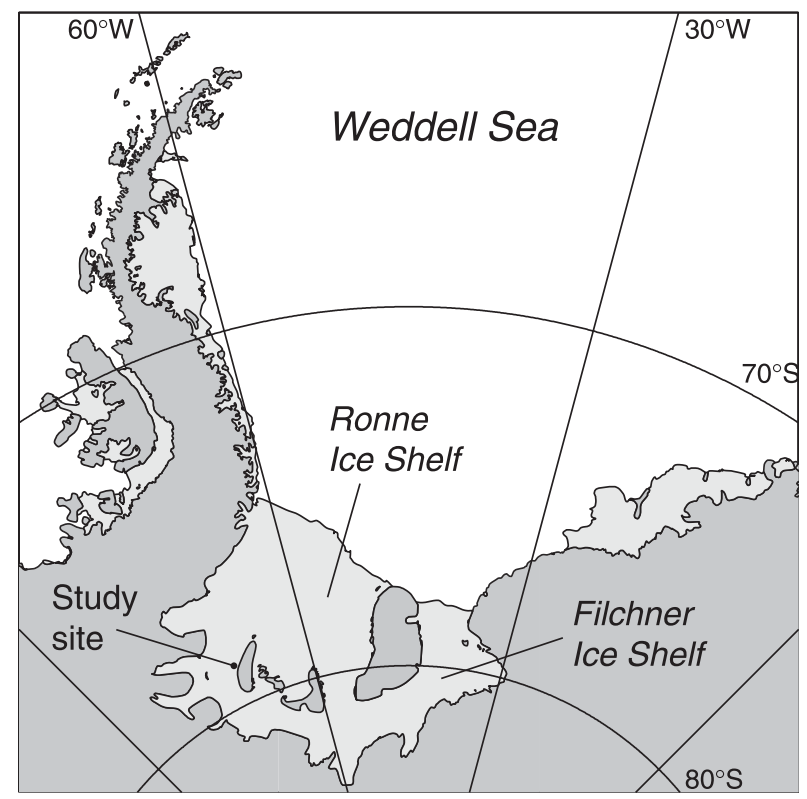

FIG. 1. Map showing the location of the study site on the Ronne Ice Shelf.

the various parameterizations of the process that have been used in models of ocean circulation beneath ice shelves. Next, we describe the phase-sensitive radar data and their interpretation in terms of the average basal ablation rate. The ocean data are then discussed and used to derive best estimates of the temperature and flow of the water near the ice-ocean interface over the year of the radar observations. We then use these temperatures and currents to calculate time series of ablation rate using a number of formulations for bulk scalar transfer through the boundary layer and compare the averages with the ablation rates measured by the radar. Finally, we suggest an optimal set of equations and parameters for use in models of the ocean circulation beneath ice shelves.

\section{Scalar transfer through the ice-ocean boundary layer}

The turbulent ice-ocean boundary layer can be conceptually divided into two regions: the surface layer, typically a few meters thick, where turbulent mixing is influenced by the proximity of the boundary and the outer layer, which typically extends over a few tens of meters, where the turbulence is unaffected by the boundary and rotation and stratification provide the main controls on mixing (McPhee 2008). Within the surface layer, an interfacial sublayer, where the transfer of momentum occurs predominantly through molecular viscosity and direct interaction of the flow with surface roughness 
elements, occupies the few millimeters up to centimeters closest to the ice-ocean interface. Seawater has a high molecular Prandtl number (ratio of kinematic viscosity to thermal diffusivity) and a very high molecular Schmidt number (ratio of kinematic viscosity to haline diffusivity), so a comparatively large part of the temperature and salinity changes between the interface and the far field occur over the interfacial sublayer (Steele et al. 1989), resulting in relatively uniform scalar concentrations beyond the sublayer and frequently the formation of a distinct mixed layer. Consequently, expressions for scalar transfer through the ice-ocean boundary layer tend to be dominated by parameterizations of the interfacial sublayer and show little sensitivity to the treatment of mixing in the remainder of the surface and outer layers (McPhee et al. 1987).

Diagnosis of the ablation rate at the base of an ice shelf requires a consideration of the heat balance at the phase change interface. We can express this as

$$
\rho_{i} a_{b} L_{i}=\left.\rho_{i} c_{i} \kappa_{i} \frac{\partial T_{i}}{\partial z}\right|_{b}-\rho_{w} c_{w} u_{*} \Gamma_{T}\left[T_{f}\left(S_{b}, P_{b}\right)-T_{w}\right],
$$

where $\rho$ is density, $L$ is latent heat of fusion, $c$ is specific heat capacity, $\kappa$ is thermal diffusivity, $T$ is temperature, $S$ is salinity, and $P$ is pressure; the subscripts $i, b, w$, and $f$ refer to ice, ice-ocean boundary, water, and the freezing point, respectively. The ablation rate at the ice-ocean boundary, $a_{b}$, is expressed as a change in thickness of solid ice per unit time, is positive for ablation, and is determined by the divergence of the sensible heat flux at the phase change interface. The first term on the righthand side is the conductive heat flux into the ice, while the second term represents the turbulent heat flux through the oceanic boundary layer. Quantification of this latter term, via a simple turbulence closure, is the main aim of this paper. The closure used in (1) and throughout this paper expresses the heat flux as the product of the interfacial friction velocity $u_{*}$, a dimensionless, turbulent transfer coefficient for heat, $\Gamma_{T}$, and the difference in temperature between the ice-ocean interface (assumed to be at the freezing point in situ) and the outer edge of the boundary layer. In practice, if well-mixed conditions develop over part of the boundary layer, $T_{w}$ corresponds to the temperature of the mixed layer. The definition of the turbulent transfer coefficient,

$$
\Gamma_{T} \equiv \frac{q_{b}^{T}}{\rho_{w} c_{w} u_{*}\left[T_{f}\left(S_{b}, P_{b}\right)-T_{w}\right]},
$$

where $q_{b}^{T}$ is the turbulent heat flux, is analogous to that of a thermal Stanton number, except for the use in the
TABLE 1. Values of physical constants.

\begin{tabular}{lll}
\hline \hline Symbol & \multicolumn{1}{c}{ Value } & \multicolumn{1}{c}{ Description } \\
\hline$\rho_{i}$ & $916 \mathrm{~kg} \mathrm{~m}^{-3}$ & Density of ice \\
$L_{i}$ & $334000 \mathrm{~J} \mathrm{~kg}^{-1}$ & Latent heat of fusion of ice \\
$\rho_{i} c_{i} \kappa_{i}$ & $2.1{\mathrm{~W}{ }^{\circ} \mathrm{C}^{-1} \mathrm{~m}^{-1}}^{\text {Thermal conductivity of ice }}$ \\
$\rho_{w}$ & $1030 \mathrm{~kg} \mathrm{~m}^{-3}$ & Seawater density \\
$c_{w}$ & $3974 \mathrm{~J}^{\circ} \mathrm{C}^{-1} \mathrm{~kg}^{-1}$ & $\begin{array}{l}\text { Specific heat capacity } \\
\text { of seawater }\end{array}$ \\
$\lambda_{1}$ & $-0.0573^{\circ} \mathrm{C}$ & Liquidus slope \\
$\lambda_{2}$ & $0.0832^{\circ} \mathrm{C}$ & Liquidus intercept \\
$\lambda_{3}$ & $-7.53 \times 10^{-8}{ }^{\circ} \mathrm{C} \mathrm{Pa}^{-1}$ & Liquidus pressure coefficient \\
\hline
\end{tabular}

denominator of the friction velocity, rather than the velocity of the boundary flow. The friction velocity is the square root of the kinematic stress at the ice-ocean interface and is normally assumed to be related to the freestream current beyond the boundary layer $U$, through a quadratic drag law,

$$
u_{*}^{2}=C_{d} U^{2},
$$

where $C_{d}$ is a dimensionless drag coefficient. Use of Eq. (3) to estimate the friction velocity introduces a second dimensionless coefficient, so the use of the friction velocity in Eq. (2) might appear disadvantageous. However, the main impact of the interfacial roughness is on the transfer of momentum through the boundary layer, and that is now parameterized through the drag coefficient. The dependence of the turbulent transfer coefficient defined in Eq. (2) on the surface roughness is thus minimized, with the result that a constant value should have broad applicability (McPhee et al. 2008).

The freezing point of seawater is generally taken to be a linear function of both salinity and pressure:

$$
T_{f}=\lambda_{1} S+\lambda_{2}+\lambda_{3} P
$$

The most accurate form of Eq. (4) is slightly nonlinear in salinity (Millero 1978), but the coefficients $\lambda_{1}$ and $\lambda_{2}$ (Table 1) are chosen to optimize the fit of the linearized form at typical seawater salinities. The interfacial salinity required in Eq. (1), $S_{b}$, is diagnosed from consideration of the salt balance at the phase change interface,

$$
\rho_{i} a_{b}\left(S_{b}-S_{i}\right)=-\rho_{w} u * \Gamma_{S}\left(S_{b}-S_{w}\right),
$$

where the diffusive salt flux in the ice shelf is zero and the salinity of the ice $S_{i}$ is generally taken to be zero. The turbulent transfer coefficient for salt $\Gamma_{S}$ (a diffusion Stanton number based on friction velocity) is much smaller than the equivalent coefficient for heat because of the dominant role played by molecular diffusion within the interfacial sublayer (Steele et al. 1989). 
While most of the terms in the above equations are either physical constants or properties of water and ice that can be relatively easily observed, the same cannot be said of the drag coefficient and the turbulent transfer coefficients, which represent simple parameterizations of the effects of turbulence in the boundary layer. A suitable drag coefficient is arguably the biggest unknown in the above system of equations. It is normally assumed that the drag coefficient at the ice shelf base will have a value similar to that at the seabed, but little is actually known about the roughness characteristics of an ice shelf base, other than that they can be highly variable (Nicholls et al. 2006). A constant value, close to the 0.0025 first used by MacAyeal (1984), is usually adopted. Various approaches to the specification of the turbulent transfer coefficients have been followed. The simplest (Determann and Gerdes 1994) considered only heat transfer and made an implicit assumption that the far-field velocity was constant. Hellmer and Olbers (1989) and Scheduikat and Olbers (1990) considered the transfer of both heat and salt but made the same implicit assumption of constant velocity. Jenkins (1991) also considered both heat and salt transfer but introduced a velocity dependence into the expressions for the turbulent heat and salt fluxes. Below we describe these three approaches in more detail along with two analogous parameterizations developed for and validated on the boundary layer beneath sea ice (McPhee et al. 2008).

The earliest parameterizations of turbulent heat and salt transfer through the oceanic boundary layer at the base of an ice shelf were those of Hellmer and Olbers (1989) and Scheduikat and Olbers (1990). They introduced slightly modified versions of Eqs. (1), (4), and (5) in which they adopted constant values for $u_{*} \Gamma_{T, S}$ and denoted these dimensional turbulent transfer velocities as $\gamma_{T, S}$. Determann and Gerdes (1994) used the same expression for the heat transfer but dropped the salt transfer equation and set the boundary salinity equal to the far-field salinity. Their use of the same numerical value for the heat transfer coefficient meant an implicit assumption of infinitely fast salt diffusion. This simpler formulation was subsequently incorporated into the models of Grosfeld et al. (1997) and Little et al. (2008).

Jenkins (1991) used the equations and notation of Hellmer and Olbers (1989) but expressed the turbulent transfer velocities as a function of the mixed layer current so that, apart from the notation, the formulation was identical to Eqs. (1)-(5). In deriving expressions for the turbulent transfer velocities Jenkins (1991) followed the approach of McPhee et al. (1987), but in the absence of any knowledge of the ice shelf basal roughness Jenkins (1991) assumed the ice shelf base to be hydraulically smooth. The formulation was based on the laboratory studies of Kader and Yaglom $(1972,1977)$ and has been widely used for modeling the interaction between ice shelves and the ocean (Jenkins and Bombosch 1995; Beckmann et al. 1999; Holland and Jenkins 2001; Holland and Feltham 2006). The application of a laboratory result to the stable, planetary boundary layer beneath an ice shelf might seem questionable. However, Holland and Jenkins (1999) showed that it yields similar results to those produced by a more complex parameterization that includes the effects both of rotation and of the stabilizing buoyancy flux caused by freshwater production at the ice-ocean interface (McPhee et al. 1987). The insensitivity to the parameterization of mixing beyond the interfacial sublayer arises because of the dominance of molecular diffusion within the sublayer in setting the overall heat and salt differences across the boundary layer.

Some authors who have followed the approach of Jenkins (1991) have used slightly different notation in which $\gamma_{T, S}$ denotes dimensionless transfer coefficients that include a factor of $C_{d}^{1 / 2}$. Such notation makes explicit the direct dependence of the equivalents of Eqs. (1) and (5) on water speed, which appears in place of the friction velocity, but leaves an implicit statement of the assumed drag law within the expressions for the transfer coefficients. In this form the transfer coefficients conform to the usual definition of thermal and diffusion Stanton numbers, with the water speed in place of the fiction velocity in the denominator of Eq. (2). In this paper we prefer the more general form given in Eqs. (1) to (5) since it leaves the turbulence closures chosen for momentum, heat, and salt independent of each other. We also adopt notation and terminology that differentiate between a dimensionless transfer coefficient (upper case) and a dimensioned transfer velocity (lower case). We note, however, that our observations do not provide us with enough information to evaluate the drag coefficient and the turbulent transfer coefficients independently. We can only place constraints on the products of drag and turbulent transfer coefficients and must rely on assumptions about the value of one to derive the other.

The preceding discussion summarizes what are, to our knowledge, all the approaches that have been taken to simulate the basal ablation of ice shelves. In the time since their introduction, a number of studies of the turbulent boundary layer beneath sea ice have updated and refined the work of McPhee et al. (1987), which was the motivation behind the velocity dependent formulations. As part of this study, we investigate the application of these new insights, discussed below, to the ice shelfocean boundary layer.

McPhee (1992) and McPhee et al. (1999) explored the use of a somewhat simpler version of Eq. (1): 


$$
\rho_{i} a_{b} L_{i}=\left.\rho_{i} c_{i} \kappa_{i} \frac{\partial T_{i}}{\partial z}\right|_{b}-\rho_{w} c_{w} u_{*} \Gamma_{\{T S\}}\left[T_{f}\left(S_{w}, P_{b}\right)-T_{w}\right],
$$

where the turbulent transfer coefficient $\Gamma_{\{T S\}}$ was found to be nearly constant with a value of around 0.006 . Note that the freezing point in the last term on the right-hand side is evaluated using the far-field salinity, rendering Eq. (5) obsolete. Equations (4) and (6) were found to give a better fit to data obtained beneath sea ice under a wide range of conditions, particularly for very smooth ice, than a combination of Eqs. (1), (4), and (5) with turbulent transfer coefficients formulated for hydraulically rough surfaces (McPhee et al. 1987). Equation (6) is analogous to that used by Determann and Gerdes (1994), the differences being their use of a dimensioned turbulent transfer velocity $\left(u_{*} \Gamma_{\{T S\}}\right)$, which we will henceforth denote $\gamma_{\{T S\}}$, and their implicit assumption of a constant far-field current. However, the dimensionless turbulent transfer coefficient introduced by McPhee (1992), being derived directly from observations, takes implicit account of the rate-limiting process of salt diffusion, and $\mathrm{McPhee}$ et al. (2008) discuss the differing numerical values of $\Gamma_{T}$ and $\Gamma_{\{T S\}}$ that are the result of this double-diffusive effect.

A relationship between $\Gamma_{T}$ and $\Gamma_{\{T S\}}$ can be derived from our earlier equations, given some simplifying assumptions. Using Eq. (4), we can show that the temperature differences in Eqs. (1) and (6) are related by

$$
T_{f}\left(S_{w}, P_{b}\right)-T_{w}=T_{f}\left(S_{b}, P_{b}\right)-T_{w}-\lambda_{1}\left(S_{b}-S_{w}\right) .
$$

It follows that, for the turbulent heat fluxes given by the last terms on the right-hand sides of Eqs. (1) and (6) to be numerically equal, the turbulent transfer coefficients must be related as follows:

$$
\frac{\Gamma_{T}}{\Gamma_{\{T S\}}}=1-\lambda_{1}\left[\frac{S_{b}-S_{w}}{T_{f}\left(S_{b}, P_{b}\right)-T_{w}}\right] .
$$

Combining Eqs. (1) and (5) and ignoring the less significant first term on the rhs of Eq. (1), we can write an expression for the last term in parentheses in Eq. (8):

$$
\frac{S_{b}-S_{w}}{T_{f}\left(S_{b}, P_{b}\right)-T_{w}}=\frac{c_{w}\left(S_{b}-S_{i}\right)}{L_{i}\left(\Gamma_{S} / \Gamma_{T}\right)} .
$$

Since the turbulent transfer coefficients for heat and salt tend to be dominated by the parameterization of molecular diffusion within the interfacial sublayer, the ratio that appears in the denominator on the rhs of Eq. (9) is nearly constant. If the salinity difference that appears in the numerator were also assumed constant, the expression in Eq. (9) would itself be constant, and to a good approximation $\Gamma_{T}$ and $\Gamma_{\{T S\}}$ would be related via a constant factor. Under these circumstances Eqs. (1) and (5) would be well approximated by (6). Note that the expression in Eq. (9) is always positive, so $\Gamma_{T}>\Gamma_{\{T S\}}$ always, reflecting the reduction in the temperature difference across the boundary layer caused by the lowered salinity at the ablating interface [Eq. (7)]. The size of this double-diffusive effect is dependent on the relative sizes of $\Gamma_{T}$ and $\Gamma_{S}$; the smaller the latter is relative to the former, the greater the difference between $\Gamma_{T}$ and $\Gamma_{\{T S\}}$. As an aside, we note further that $\Gamma_{T}>\Gamma_{\{T S\}}$ would remain true even if $\Gamma_{T}$ and $\Gamma_{S}$ were numerically identical and that the statement $\Gamma_{T}=\Gamma_{\{T S\}}$ requires $\Gamma_{S}$ to be infinite.

From the foregoing discussion, we conclude that the representation of Eqs. (1), (4), and (5) by the reduced set of Eqs. (4) and (6) is only as good as the approximation made in equating the ratio in Eq. (8) to a constant value. The necessary assumptions will be poor wherever $S_{b}$ varies widely or the heat conduction term neglected in the derivation of Eq. (9) plays an important role. We note that the approximation is likely to be better beneath ice shelves, where the thick ice cover isolates the ice-ocean interface from the influence of the atmosphere, than beneath sea ice. The thermal insulation provided by an ice shelf ensures that the first term on the rhs of Eq. (1) is small and subject to little variability at its base and that solar heating of the ocean, responsible for the highest levels of thermal forcing and hence the lowest values of $S_{b}$ beneath sea ice, can never play a significant role in driving ablation at its base. Nevertheless, temperatures nearly $4^{\circ} \mathrm{C}$ above the freezing point in situ have been observed near Antarctic ice shelves (Jacobs et al. 1996) and even higher values have been recorded in Greenland fjords (D. M. Holland et al. 2008). If temperatures as high as these were present within the turbulent boundary layer, the boundary salinity could fall below 15 psu and the use of Eq. (6) with a turbulent transfer coefficient evaluated for less extreme conditions would be inappropriate.

McPhee et al. (2008) present a formulation analogous to Eqs. (1)-(5), where the turbulent transfer coefficients for heat and salt take constant values. Those values are chosen such that the calculated heat flux matches that given by Eq. (6) under conditions typical of those under which the observations of the turbulent ice-ocean boundary layer have been made. McPhee et al. argue that, although the value of $\Gamma_{\{T S\}}$ used in Eq. (6) is the one that can be most reliably inferred from observation, theory implies that under more extreme forcing the differing rates of diffusion for heat and salt in the interfacial sublayer will become important. These are the conditions under 
which the rhs of Eq. (9) is no longer constant and, in some cases such as when the ice cover is very thin, direct observation of the turbulent heat flux becomes impossible. To evaluate the ice-ocean heat flux under the full range of possible conditions McPhee et al. (2008) propose that Eqs. (1) and (5) with constant transfer coefficients represents the simplest possible extension of Eq. (6) and argue that at present the observations do not demonstrate the need for any greater complexity. Notz et al. (2003) showed that, using such a model, the iceocean heat flux could be correctly diagnosed under at least one set of conditions in which Eq. (6) failed. Therefore, in addition to testing the parameterizations of ice-ocean heat transfer that have been used to evaluate ablation at the base of ice shelves, we also follow the reasoning of McPhee et al. in investigating the use of both Eq. (6) and Eqs. (1) and (5) with constant transfer coefficients.

We note that McPhee et al. (2008) also discussed the freezing process and suggested that the absence of any supercooling in observations made in the boundary layer beneath growing sea ice argued for the use of the same transfer coefficient for both heat and salt in the case of freezing. Beneath ice shelves the process of basal accumulation differs substantially from that of ablation. Evidence suggests that most ice grows in the water column as suspended frazil crystals that subsequently settle onto the ice shelf base, and modeling the details of this process requires a very different approach (Jenkins and Bombosch 1995; Smedsrud and Jenkins 2004). A simple parameterization might use the same equations as those presented here for modeling ablation but enhance the heat flux through the use of much larger turbulent transfer coefficients. However, a detailed discussion of this point is beyond the scope of this paper, and in what follows we will concern ourselves with the process of ablation only.

\section{Direct measurements of basal ablation}

We determine the ablation rate at the base of the ice shelf from measurements of the rate of change of the ice shelf thickness using ice-penetrating radar. The total thickness change is the net result of snow accumulation at the surface, compaction of the upper layers of snow and firn as they are converted into solid ice, vertical compression of the entire ice column in response to the divergence of the horizontal ice flow, and ablation at the lower surface. By observing the movement of internal layers within the column of ice and firn, and deriving the movement of the ice shelf base relative to these, we can eliminate the processes of accumulation and compaction, quantify the vertical strain rate, and hence isolate

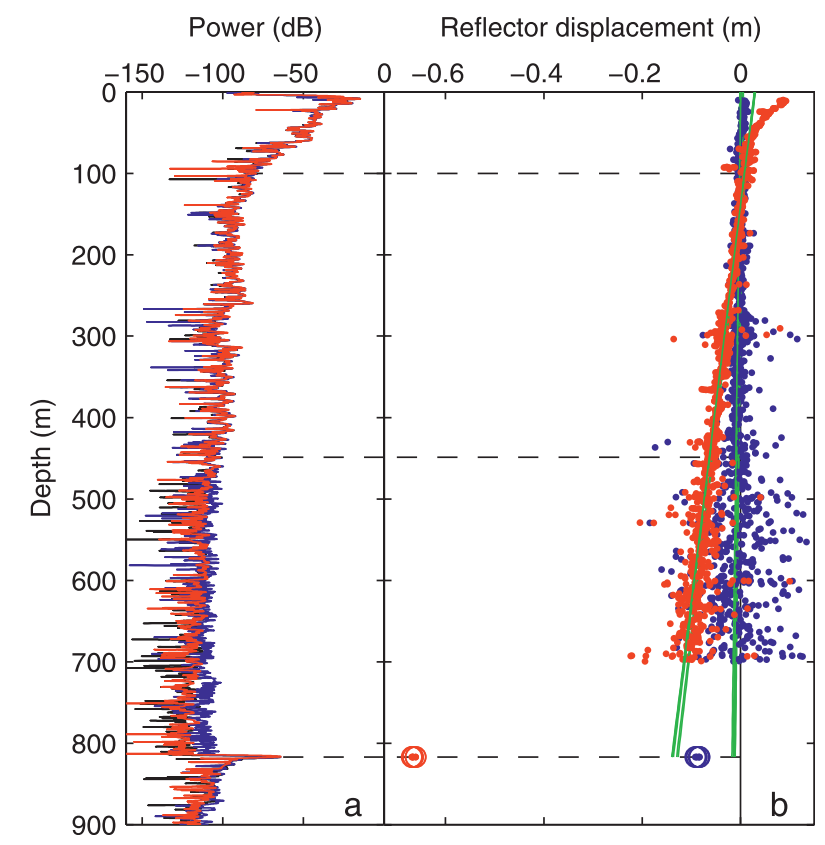

FIG. 2. (a) Radar records obtained at the site shown in Fig. 1 on 2 Jan (black), 8 Feb (blue), and 19 Dec 2001 (red) and (b) reflector displacement between the time of the first and second observations (blue) and between the time of the first and third observations (red). In each case the green lines are best linear fits to the displacement data lying between the upper two horizontal dashed lines. The lower horizontal dashed line indicates the depth of the basal reflector, where the measured displacements (circled dots) lie to the left of the green lines by an amount equal to the loss of ice by basal ablation over the period between the observations.

the component of the thinning signature that is the result of bottom ablation only.

Figure 2a shows three typical radar records obtained at the study site (Fig. 1) on 2 January, 8 February, and 19 December 2001. The radar was set up on the ice shelf surface with transmit and receive antennas separated by a horizontal distance of $5 \mathrm{~m}$. The traces in Fig. 2a show signal strength versus depth, the latter being derived from the measured two-way travel time of the signal and an assumed constant velocity for electromagnetic waves in ice. The radar signal is reflected from discontinuities within the ice shelf as well as from the ice-seawater interface at the base of the ice shelf. The power received from the internal discontinuities falls away with distance because of the geometric spreading of the wave front and radar absorption within the ice. However, a distinct and reproducible pattern can be seen, at least down to $450 \mathrm{~m}$, beyond which depth the reflected power drops below about $-120 \mathrm{~dB}$, the typical level of the background environmental and system noise. The reflection from the ice shelf base at $816 \mathrm{~m}$ comes in well above the noise level. The basal reflection is much stronger than the internal reflections because the extreme contrast in 
dielectric properties between the ice and seawater reflects almost all of the incident energy.

Because the pattern of internal reflections shallower than $450 \mathrm{~m}$ is so reproducible, we can correlate the original record with the repeats to derive the change in depth of each of the reflectors over the time interval between the observations. The depth change is plotted as a function of the original reflector depth in Fig. 2b. The high precision of these measurements is obtained because we record both amplitude (plotted in Fig. 2a) and phase of the received radar signal. From the phase difference between successive observations we can calculate the change in depth of any reflector to a small fraction $(\sim 1 \%)$ of a wavelength $(59.8 \mathrm{~cm}$ in ice), giving subcentimeter precision in the measurements. The correlation of the radar amplitudes is then only needed to determine the number of whole wavelengths to add to the displacement calculated from the phase difference to give the total relative motion of the reflectors.

The reflector displacements plotted in Fig. 2b were calculated over the periods from 2 January to 8 February (37 days) and 2 January to 19 December 2001 (351 days). For each date, data from six closely spaced radar soundings are included in Fig. 2b, whereas only one of the six is shown for each case in Fig. 2a. At the subcentimeter level of interest here, the ice shelf surface is not a suitable reference point as we disturb the snow surface each time we make the measurements. For this reason, displacements in Fig. $2 \mathrm{~b}$ are plotted relative to a strong internal reflector at a nominal depth of $119 \mathrm{~m}$. The pattern of negative displacement beneath the reference horizon and positive displacement above implies that in all cases the distance between the reflectors and the reference has decreased over time.

The data in Fig. $2 b$ indicate that the ice shelf overall is thinning and that all of the internal reflectors are coming closer together. The latter is the manifestation of the vertical convergence that balances the horizontal divergence of the ice shelf flow. In the upper layers vertical convergence is enhanced as the low density layers of snow and firn are compacted into solid ice. Since the horizontal flow of the ice shelf is independent of depth and the compaction signal is negligible by about $100-\mathrm{m}$ depth, the displacement of the deeper reflectors should be a linear function of depth. In Fig. 2b, we plot least squares linear fits (six for each measurement epoch) to the displacement data obtained between 100 and $450 \mathrm{~m}$ depth. We do not use data from below $450 \mathrm{~m}$ because of the poorer signal-to-noise ratio, although they clearly follow the same linear trends. Extrapolation of the linear trends to the depth of the ice shelf base tells us how much of the observed ice shelf thinning is a result of horizontal divergence in the ice flow. The difference between this and the observed displacement of the basal reflector is the result of ablation. We find that over the 2 January to 8 February period the basal ablation rate averaged $0.733 \pm 0.018 \mathrm{~m} \mathrm{yr}^{-1}$, whereas the overall average for the full 2 January to 19 December period was $0.554 \pm 0.006 \mathrm{~m} \mathrm{yr}^{-1}$. The error estimates are a combination of the standard errors derived from the scatter in the results obtained from the six independent observations for each time interval and an estimated 1\% uncertainty in the electromagnetic wave speed used to convert differences in the two-way travel time to displacements.

A further set of six measurements was made at the same site on 4 February 2001, but the data from this visit and the reflector displacements determined over the 33-day interval from the original observation are omitted from Fig. 2 for clarity. We find that over this shorter period the basal ablation rate averaged $0.698 \pm$ $0.019 \mathrm{~m} \mathrm{yr}^{-1}$, suggesting a peak in ablation near the start of February.

\section{Observations of the water column beneath the ice shelf}

The oceanographic measurements made at the study site in January 1996 were described by Nicholls et al. (1997), while some of the longer-term records were discussed by Nicholls and Makinson (1998) and Jenkins et al. (2004). Two current meters and five conductivitytemperature (CT) units left in the water column (Nicholls and Makinson 1998) yielded records of varying length, but none lasted until the time of the radar observations. However, a thermistor cable was also deployed to record temperatures within about 20-25 m of the ice shelf base and this was logged until November 2002. Over the period of the radar measurements, the temperatures were logged every $15 \mathrm{~min}$.

The techniques used to construct, calibrate, and monitor the thermistor cable are described by Nicholls (1996). Although the precision of the temperature records is a few millidegrees kelvin, the absolute accuracy is poorer than this owing to the uncertain response of the thermistors to pressure. The absolute accuracy, or more precisely the accuracy of the measurement of the deviation of the temperature from the freezing point at the base of the ice shelf, is important as this is one of the principal drivers of the ablation. Here we set the absolute level of the temperature records by assuming that the minimum recorded temperature is the freezing point at the base of the ice shelf. The minimum was seen in September 1997, with the same temperature again being attained in November 2001. As the field site was in a region of basal ablation, it is reasonable to assume that the water never becomes supercooled in situ. This assumption is 
supported by the current meter data, which showed the water flowing as a southward current throughout the water column, that is, from a region of shallower ice. Water interacting with a shallower ice base would be likely to have a temperature higher than the freezing point at the deeper basal ice at the study site. Although we have good grounds to rule out supercooling, it is possible that even the lowest temperature observed over the 6.5-yr period was, in fact, above the freezing point in situ. Our calibration procedure thus yields temperatures that represent both a best estimate and a lower bound on the possible values.

The only available independent check is from the temperature profiles obtained during conductivitytemperature-depth (CTD) casts made just before the thermistor cables were installed. A series of profiles were obtained between 21 and 22 February 1996-3.5 days before the first thermistor cable data. The profiles gave the temperatures near the ice shelf base as $-2.40^{\circ} \mathrm{C}$, within a few millidegrees of the lowest calibrated temperature measured by the thermistor nearest the ice base during the subsequent two months. Since the calibrated temperatures from the thermistors are themselves a lower bound, the CTD profiling offers some confirmation of the calibration procedure described above: if the thermistor temperatures were substantially too low, needing to be corrected upward, such an adjustment would make the temperatures recorded during the profiling appear anomalously low. Based on this reasoning we place an estimate of $+0.01^{\circ} \mathrm{C}$ on the uncertainty of the temperatures from the thermistors.

As we have calibrated our temperature record with respect to the freezing point, the absolute value of salinity is not critical and salinity fluctuations have only a small impact on the freezing point. Salinity measurements were obtained during the initial CTD profiling of the water column and through the lifetime of the CT units, which lasted up to $2.75 \mathrm{yr}$. In the calculations described in the next section we use the mean salinity observed within the mixed layer during the profiling and assume this value (34.51 psu) to be constant. The CT unit situated $20 \mathrm{~m}$ below the ice shelf base recorded salinity fluctuations of up to 0.1 , which would cause the freezing point to vary by up to $0.005^{\circ} \mathrm{C}$.

We have a number of thermistors at varying depths below the ice shelf base from which to take a far-field temperature record that is consistent with the simple parameterizations of the boundary layer discussed in section 2. Under steady forcing, we would expect to see relatively well-mixed conditions over much of the boundary layer, in which case a measurement from any point within the mixed layer would suffice. However, the temperatures in the upper $25 \mathrm{~m}$ of the water column, shown in
Fig. 3 for the period of the short-term radar measurements from January to early February 2001, show more complex structures and much variability. Although relatively wellmixed conditions are frequently seen, sometimes underlain by a relatively sharp thermocline, this is not universally the case. The mixed layer occasionally thins to no more than a few meters, with the penetration of warmth toward the ice base and thermal stratification over much of the upper $25 \mathrm{~m}$ of the water column (e.g., 26-30 January).

The temperature record from a little less than $2 \mathrm{~m}$ below the ice shelf base is shown in Fig. 4 for the entire period of the radar measurements. This thermistor was closest to the ice base, but well outside the interfacial sublayer, and sampled the well-mixed part of the boundary layer. Although this is not the measurement from the outer edge of the boundary layer called for by the parameterizations of section 2 , we argue that the records from the deeper thermistors will be warm biased because of the periods spent outside the mixed layer. We justify the use of temperatures recorded within the boundary layer a posteriori, by the consistency of the results obtained from several thermistors placed within about $5 \mathrm{~m}$ of the ice shelf base, compared with the rising ablation rates obtained using water temperatures measured at greater distances from the ice.

The record from the uppermost thermistor (Fig. 4) shows a rapid warming of just over $0.1^{\circ} \mathrm{C}$ during January, with peak temperatures occurring toward the end of the month when the mixed layer shoaled markedly (Fig. 3), followed by a gradual decline. This annual temperature cycle is similar to that observed in earlier years (Nicholls and Makinson 1998; Jenkins et al. 2004), although the warming, attributed to the arrival of a pulse of high salinity shelf water generated at the ice front during the preceding winter, is somewhat later and of shorter duration. The timing of the temperature maximum is consistent with the inference from the radar measurements of peak ablation around the start of February (section 3).

The current meter located $20 \mathrm{~m}$ below the ice base gave a record of only 18 days duration from 26 January to 13 February 1998. A second current meter suspended $80 \mathrm{~m}$ above the seabed (about $400 \mathrm{~m}$ below the ice shelf base) yielded a 24-month dataset covering the period from 26 February 1996 until 19 March 1998. In some of the formulations discussed in section 2 scalar transfer through the ice-ocean boundary layer is assumed to be linearly dependent on the water speed, so we need to use the available data to estimate the currents during 2001. In the absence of evidence to the contrary, we assume that both current meters sampled the free-stream current beyond the boundary layer, as called for in Eq. (3).

The currents recorded at both levels in the water column are dominated by tidal activity: the upper and 

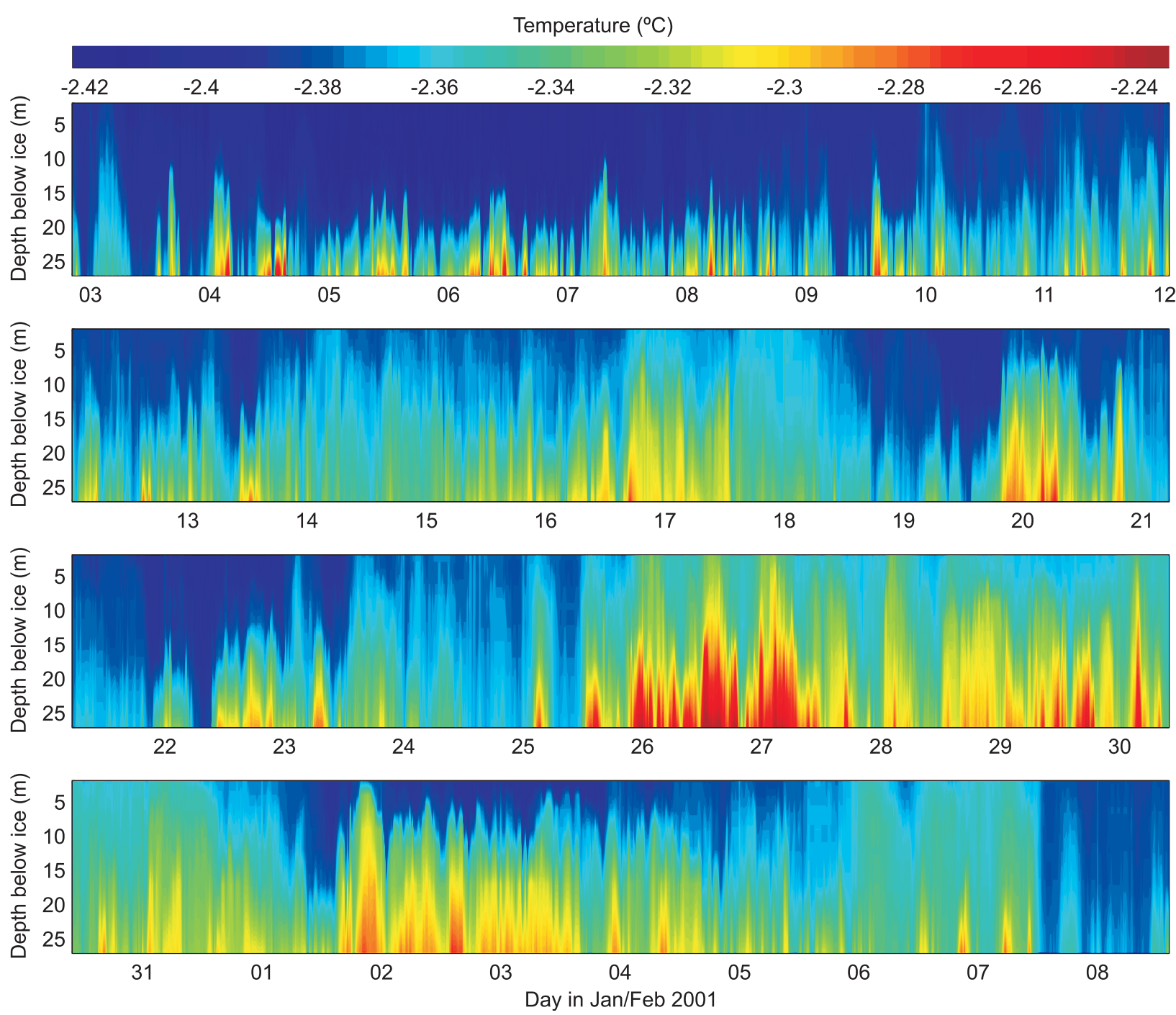

FIG. 3. Water temperatures in the upper $25 \mathrm{~m}$ of the water column from 2 Jan to 8 Feb 2001.

lower instruments give mean current values of 2.7 and $3.6 \mathrm{~cm} \mathrm{~s}^{-1}$, respectively, with a typical water speed during spring tides $\sim 20 \mathrm{~cm} \mathrm{~s}^{-1}$. This dominance allows us to estimate the principal contributor to the currents at the site during 2001 by calculating the tidal components from harmonic analysis of the current meter records and then predicting the tides for the period covering the radar measurements. Harmonic analysis of the longer record from the deeper current meter accounted for over $90 \%$ of the variance. During the 2-yr-long record, the nontidal background velocity component varied by around $\pm 1 \mathrm{~cm} \mathrm{~s}^{-1}$. We assume that the lowfrequency variations in the velocity of the upper water column are similarly weak and combine the mean current with the tidal predictions to estimate the water speed.

\section{Basal ablation rates derived from oceanographic data}

First we use Eqs. (1)-(5) and the turbulent transfer coefficients introduced by Jenkins (1991) to calculate the basal ablation rate at the study site. Equation (1) requires the temperature gradient within the ice at the ice shelf base. Thermistors frozen into the ice shelf provided a value of $-0.35^{\circ} \mathrm{C} \mathrm{m}^{-1}$. We used the physical properties of ice and seawater, given in Table 1 , and a value of 0.0025 for the drag coefficient (MacAyeal 1984). Figure 5 shows the time series of water temperature, speed, and the calculated basal ablation rates for the period from 2 January to 8 February 2001, that is, the period of the short-term radar measurements. The temperatures used for this figure were from the thermistor nearest the ice 


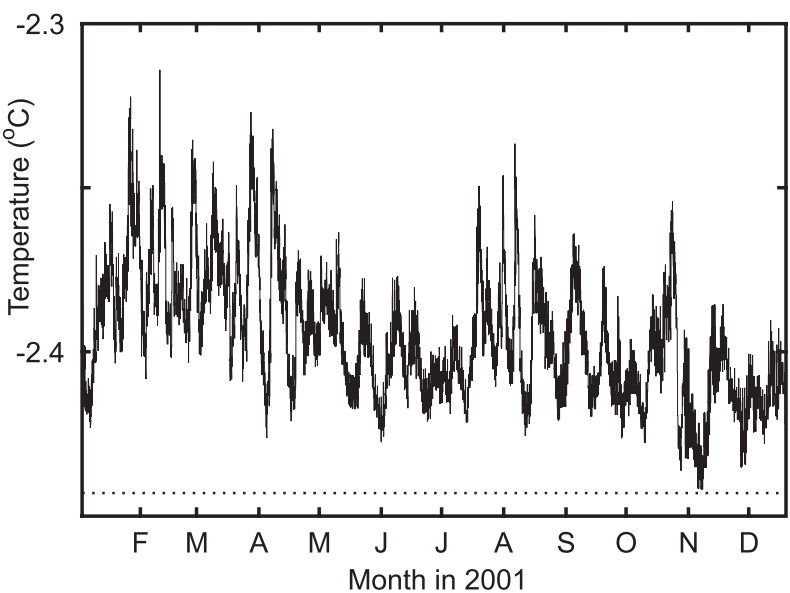

FIG. 4. Water temperatures from 2 Jan to 19 Dec 2001 at a nominal distance of $1.9 \mathrm{~m}$ below the ice base. The dotted line shows the seawater freezing point in situ.

base, estimated to be $1.9 \mathrm{~m}$ below the ice-ocean interface by the end of 2001. The upper panel of the figure shows that the peak temperature attained near the ice base was over $0.1^{\circ} \mathrm{C}$ higher than the freezing temperature in situ, resulting in calculated instantaneous ablation rates of nearly $2.5 \mathrm{~m} \mathrm{yr}^{-1}$.

Figure 6 shows the dependence of the calculated mean ablation rate on the depth below the interface of the thermistor used to give the water temperature. Using temperatures from over $5 \mathrm{~m}$ from the ice base causes the calculated ablation rates to rise. The reason for this sensitivity can be seen in Fig. 4, which shows the upper mixed layer often becoming very thin. Also shown in Fig. 6 are the observed ablation rates obtained from the radar measurements. Both observed and calculated values reflect the relatively high January rates, and both discriminate the augmenting effect of including the extra four high-ablation days near the beginning of February. The calculated ablation rates are about $40 \%$ lower that the direct observations, a level of agreement consistent with the observational uncertainties and the rather arbitrary selection of the value for the drag coefficient. The best agreement would be obtained for this site using Eqs. (1)-(5) and the Jenkins (1991) expressions for the turbulent transfer coefficients with a drag coefficient of 0.0062 . We note that adjustment of this one parameter produces good agreement with all observations (Fig. 6). This value for the drag coefficient lies toward the upper end of a broad range of values derived for sea ice by a variety of methods (McPhee 1990). If we allow that the water temperature measured by the thermistors might be low by up to $0.01^{\circ} \mathrm{C}$, as previously discussed, then the calculated year-round mean ablation rate might be underestimated by as much as $0.08 \mathrm{~m} \mathrm{yr}^{-1}$. Adjusting the temperatures upward by $0.01^{\circ} \mathrm{C}$, the value for the drag coefficient
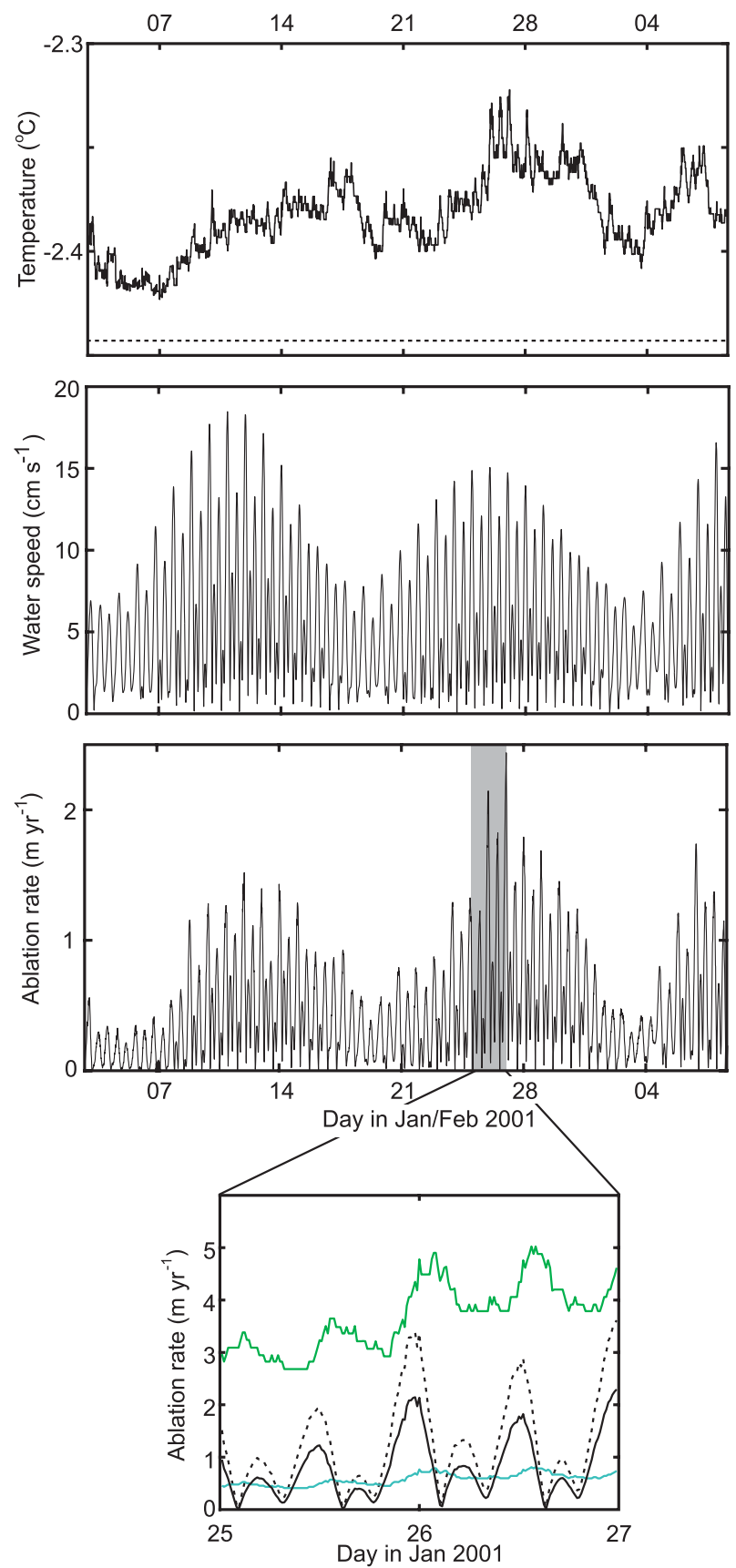

FIG. 5. (top) Water temperature measured using the sensor nominally $1.9 \mathrm{~m}$ below the ice base, (middle) estimate of the water current $20 \mathrm{~m}$ below the ice base, and (bottom) calculated basal ablation rate using Eqs. (1)-(5) and the turbulent transfer coefficients of Jenkins. In the expanded section of the bottom panel, basal ablation rates calculated using the turbulent transfer velocities of Hellmer and Olbers (cyan), Determann and Gerdes (green), and the tuned version of the Jenkins formulation with $C_{d}$ of 0.0062 (dashed) are added for comparison. 


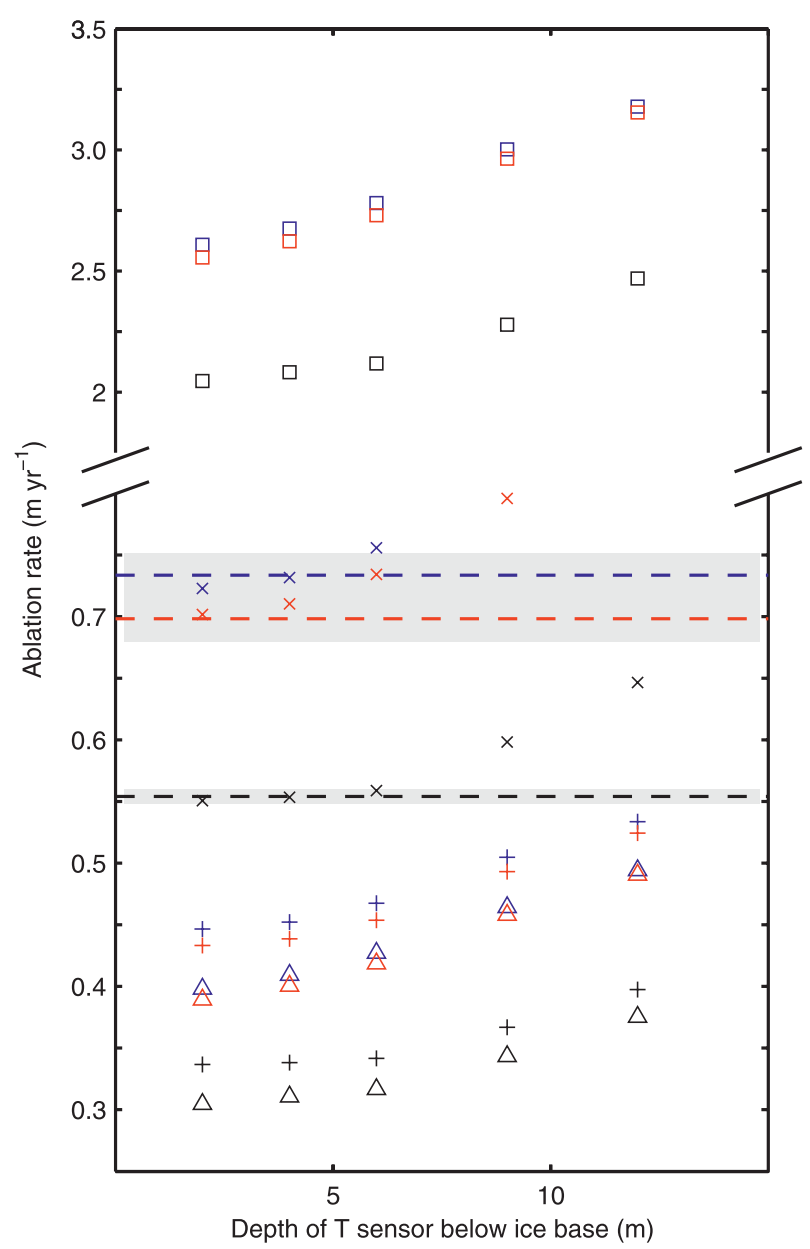

FIG. 6. Calculated ablation rates averaged over 2 Jan-4 Feb 2001 (red), 2 Jan-8 Feb 2001 (blue), and 2 Jan-19 Dec 2001 (black). The ablation rates are calculated using water temperatures measured at increasing distances from the ice shelf base. The horizontal dashed lines show the ablation rates measured using radar for the same time periods, with standard errors indicated by shading. Symbols indicate the formulation used to calculate the ablation rates: Jenkins with $C_{d}$ of $0.0025(+)$; Jenkins with $C_{d}$ of $0.0062(\times)$; Hellmer and Olbers $(\triangle)$; and Determann and Gerdes $(\square)$. Note the separate ablation rate axis in the upper half of the diagram.

required to best match the observed ablation rates is then reduced to 0.0045 . Similarly, an assumption that the velocity has been underestimated by $1 \mathrm{~cm} \mathrm{~s}^{-1}$ would give a corrected drag coefficient of 0.0044 . Accounting for both possible maximum errors would give a value of $C_{d}$ of 0.0032 . In all cases, however, the fit to both short and long term measurements is best when using the original estimates of temperature and velocity.

Also shown in Fig. 6 are the average ablation rates calculated using the other formulations that have been implemented in models of the ocean circulation beneath ice shelves, discussed in section 2. That of Hellmer and Olbers (1989) assumes a fixed water speed, but the effective value is too low for this particular environment. Computed ablation rates are reduced by about $10 \%$ compared with the Jenkins (1991) velocity-dependent model and by about $45 \%$ compared with the observations. The heat transfer is low overall because, although the heat transfer velocity of $1 \times 10^{-4} \mathrm{~m} \mathrm{~s}^{-1}$ is equivalent to the Jenkins (1991) formula if the assumed water speeds are rather high $\left(14 \mathrm{~cm} \mathrm{~s}^{-1}\right)$, the salt transfer velocity has a value of $5.05 \times 10^{-7} \mathrm{~m} \mathrm{~s}^{-1}$, equivalent to the assumption of very low water speeds $\left(2 \mathrm{~cm} \mathrm{~s}^{-1}\right)$. The formulation introduced by Determann and Gerdes (1994) yields ablation rates that are too high by a factor of $\sim 4$. Their implicit assumption about the speed of the water is clearly inappropriate for this particular site. We note that the lack of a velocity dependence in these latter two formulations means that any tuning to match observations would be site specific. The problem is highlighted in Fig. 5, where the output of all the models is compared over a 2-day period in late January. The models that respond only to temperature variations produce ablation rate series with much reduced variability. The relatively close correspondence, apparent in Fig. 6, between the mean ablation rates calculated with the models of Hellmer and Olbers (1989) and Jenkins (1991) is fortuitous and dependent on the choice of averaging period.

While good agreement between observed and calculated ablation rates can be obtained for the velocitydependent formulation of Jenkins (1991), this result is far from being a corroboration of the applicability of turbulent transfer coefficients derived from laboratory studies of heat transfer at hydraulically smooth surfaces. In particular, we have not demonstrated that the complexity of that formulation is required to explain the observed ablation rates. We therefore next follow the reasoning of McPhee et al. (2008) and seek constant values for the turbulent transfer coefficients that would optimally fit our data. Using Eq. (6) the best fit of the calculated ablation rate to the observed year-round average is obtained with $C_{d}^{1 / 2} \Gamma_{\{T S\}}$ set to $5.94 \times 10^{-4}$. Assuming that the turbulent transfer coefficient of 0.006 found by McPhee (1992) for sea ice is appropriate in this case implies that the drag coefficient must be 0.0098 . Optimizing the fit for the summer peak in ablation yields values of $5.93 \times 10^{-4}$ for $C_{d}^{1 / 2} \Gamma_{\{T S\}}$ and 0.0097 for $C_{d}$. Using Eqs. (1) and (5) in place of (6) we have two unknowns, which in principal could be tuned to optimize the fit to both year-round and summertime ablation rates simultaneously. However, given the combined uncertainties in our data, the difference between our two estimates of $C_{d}^{1 / 2} \Gamma_{\{T S\}}$ is insignificant. We therefore have no observational evidence that the additional complexity of Eqs. (1) and (5) is necessary and we lack the information needed to estimate two independent transfer coefficients. This probably reflects the 
TABLE 2. Recommended values of turbulent transfer and drag coefficients.

\begin{tabular}{lll}
\hline \hline Symbol & \multicolumn{1}{c}{ Value } & \multicolumn{1}{c}{ Description } \\
\hline$C_{d}^{1 / 2} \Gamma_{T}$ & 0.0011 & Thermal Stanton number \\
$C_{d}^{1 / 2} \Gamma_{S}$ & $3.1 \times 10^{-5}$ & Diffusion Stanton number \\
$C_{d}^{1 / 2} \Gamma_{\{T S\}}$ & $5.9 \times 10^{-4}$ & Stanton number \\
$C_{d}$ & 0.0097 & Drag coefficient \\
$\Gamma_{T}$ & 0.011 & Heat transfer coefficient \\
$\Gamma_{S}$ & $3.1 \times 10^{-4}$ & Salt transfer coefficient \\
$\Gamma_{\{T S\}}$ & 0.006 & Transfer coefficient \\
\hline
\end{tabular}

limited range of conditions sampled at our single study site, and both observations and theory suggest that a formulation that explicitly considers the differing molecular diffusivities of heat and salt will perform better over a wide range of thermal forcing. McPhee et al. (2008) argue that for an ablating ice interface the ratio of heat to salt transfer coefficient should lie somewhere in the range 35-70. Adopting a value at the lower end of this range, we find the best fit to our observations is obtained with values of 0.0011 for $C_{d}^{1 / 2} \Gamma_{T}$ and $3.1 \times 10^{-5}$ for $C_{d}^{1 / 2} \Gamma_{S}$. For a ratio at the upper end the values become 0.0016 and $2.2 \times 10^{-5}$. For a drag coefficient of 0.0097 , these values imply a heat transfer coefficient in the range $0.011-0.016$ and a salt transfer coefficient in the range $3.1 \times 10^{-4}-2.2 \times 10^{-4}$.

\section{Discussion and recommendations}

We have described a unique set of observations made deep in the interior of the Ronne Ice Shelf that have enabled us for the first time to test quantitatively a number of parameterizations of turbulent scalar fluxes through the ice-ocean boundary layer. Such parameterizations lie at the heart of all models of ocean circulation beneath ice shelves, as the phase changes that result represent one of the most important forcings on the circulation. If a parameterization gives an incorrect ablation rate, it is unlikely that the resulting circulation will be correct, unless there is a fortuitous, compensating error in some other part of the model.

Up to three turbulence closure parameters are required, namely the drag coefficient and the heat and salt transfer coefficients. We have evaluated the various choices that have been made for these parameters in the subice shelf environment to date. We find that two out of the three formulations that have been used can reproduce the observed ablation rate to within $50 \%$. While the parameterization of Jenkins (1991) can readily be tuned to match the observations, we have no evidence to justify the level of complexity involved in the expressions for the turbulent transfer coefficients. We have therefore followed the
TABLE 3. Ablation rates $\left(\mathrm{m} \mathrm{yr}^{-1}\right)$ derived from observations and recommended parameterizations.

\begin{tabular}{lccc}
\hline \hline \multicolumn{1}{c}{ Source } & 2 Jan-4 & 2 Jan-8 & 2 Jan-19 \\
Feb 2001 & Feb 2001 & Dec 2001 \\
\hline Observation & $0.698 \pm 0.019$ & $0.733 \pm 0.018$ & $0.554 \pm 0.006$ \\
Eqs. (1), (3), (4), (5) & 0.704 & 0.725 & 0.553 \\
Eqs. (3), (4), (6) & 0.709 & 0.731 & 0.550 \\
\hline
\end{tabular}

alternative strategy of McPhee et al. (2008) and chosen constant values for the turbulent transfer coefficients that best fit our observations. In practice, the more complex expressions for the coefficients (McPhee et al. 1987; Jenkins 1991) tend to yield nearly constant values under most conditions because of the dominance of molecular diffusion within the interfacial sublayer over turbulent diffusion within the surface and outer layers in determining the heat and salt profiles through the boundary layer. Indeed, the ratio of heat to salt transfer coefficients suggested by McPhee et al. (2008) comes from an assumption that the temperature and salinity at the outer edge of the interfacial sublayer are effectively equal to far-field values. Although we have several observations of the ablation rate, the relative uniformity of the oceanographic conditions on average means that we can only determine the best choice for one parameter independently. We have therefore given combinations of drag and turbulent transfer coefficients (i.e., conventional Stanton numbers) that best represent conditions at our study site and made use of the theoretical ratio of heat to salt transfer coefficients to provide appropriate values for use in Eqs. (1) and (5).

Based on the observations reported here, our overall recommendation for the calculation of the ablation rate at the base of an ice shelf is to use either Eqs. (1), (3), (4), and (5) or Eqs. (3), (4), and (6) with values for the turbulence closure parameters given in Table 2 . The mean ablation rates obtained by applying these recommended formulations over the periods of the observations and using the temperature of the upper thermistor are shown in Table 3. We have no evidence from our single study site that favors one formulation over the other, but we would anticipate that an explicit treatment of salt transfer through the boundary layer would be applicable for a broader range of oceanographic conditions and ice shelf ablation rates.

If either formulation is used in an ocean model that does not simulate the tidal currents, a potentially significant contribution to the interfacial friction velocity will be missing. In this case a modified version of Eq. (3) could be used:

$$
u_{*}^{2}=C_{d}\left(U^{2}+\left\langle U_{T}^{2}\right\rangle\right),
$$


TABLE 4. Turbulent transfer velocities $\left(\mathrm{m} \mathrm{s}^{-1}\right)$ appropriate for a selection of rms tidal currents using the coefficients from Table 2.

\begin{tabular}{lcccc}
\hline$\overline{\sqrt{\left\langle U_{T}^{2}\right\rangle}}$ & $u_{*}$ & \multicolumn{1}{c}{$\gamma_{T}$} & $\gamma_{S}$ & \multicolumn{1}{c}{$\gamma_{\{T S\}}$} \\
\hline 0.025 & 0.0025 & $0.27 \times 10^{-4}$ & $0.76 \times 10^{-6}$ & $0.15 \times 10^{-4}$ \\
0.05 & 0.0049 & $0.54 \times 10^{-4}$ & $1.5 \times 10^{-6}$ & $0.30 \times 10^{-4}$ \\
0.1 & 0.0098 & $1.1 \times 10^{-4}$ & $3.1 \times 10^{-6}$ & $0.59 \times 10^{-4}$ \\
0.2 & 0.0197 & $2.1 \times 10^{-4}$ & $6.1 \times 10^{-6}$ & $1.2 \times 10^{-4}$ \\
0.3 & 0.0295 & $3.2 \times 10^{-4}$ & $9.2 \times 10^{-6}$ & $1.8 \times 10^{-4}$ \\
\hline
\end{tabular}

where $U_{T}$ is the tidal current magnitude and the angle brackets indicate a temporal average. The mean-square tidal velocity would ideally be a spatially varying quantity based on the results of a tidal model, but, if such information were not available, a constant value based on the likely tidal current magnitude for the ice shelf in question could be adopted. In a region of high tidal currents and low temperature this latter strategy would be tantamount to choosing constant turbulent transfer velocities, as used in some of the formulations discussed in section 2. However, adopting this slightly more complex strategy would ensure that the chosen transfer coefficients were based in a quantitative fashion on an estimate of the intensity of the primary source of turbulent kinetic energy. Table 4 gives values for $\gamma_{T, S}\left(u_{\circledast} \Gamma_{T, S}\right)$ and $\gamma_{\{T S\}}\left(u_{*} \Gamma_{\{T S\}}\right)$ for a number of root-mean-square tidal currents, based on the assumption that the tides are the only source of energy for mixing. For the lower values, ignoring the mean flow could overlook a significant additional contribution to the total energy available for mixing, and the inclusion of the time-mean flow speed in Eqs. (1), (5), and (6) is critical to the recovery of the nonlinear response of ice shelf ablation to changes in the far-field ocean temperature discussed by P. R. Holland et al. (2008). For these reasons the use of constant turbulent transfer velocities is not recommended, and the values in Table 4 are given primarily for the purposes of comparison with earlier studies.

Although we have included an explicit value for the drag coefficient in our list of recommendations in Table 2, we urge caution in its use. The value has been inferred from a study of scalar, rather than momentum, transfer through the ice-ocean boundary layer and has been chosen such that the turbulent transfer coefficients for scalars are consistent with those recommended by McPhee et al. (2008) for sea ice. While we have no evidence to suggest that the sea ice results should not be directly applicable to an ice shelf, we note that the parameterizations discussed in section 2 have been derived from theory that assumes a fully developed, steady boundary layer. The temperature records shown in Fig. 3 indicate a high degree of variability, some of which must be associated with temporal evolution of the boundary layer. An inevitable result of our model fitting procedure is that any deficiencies in the theory will have been absorbed into the tuning of the drag coefficient.

In models where the vertical resolution is sufficient to resolve the surface layer, some care is required in the choice of variable to input to the parameterization of the turbulent fluxes. Values from the closest grid point to the boundary may not be the most appropriate. This is particularly true of velocity, where the free stream current beyond the boundary layer is required for the drag law in Eqs. (3) and (10). In practice, the interfacial sublayer is unlikely to be resolved, so temperature and salinity from the grid point closest to the boundary might well be the best choice, but it should be far enough from the ice shelf base to sample conditions in the well-mixed part of the boundary layer.

\section{Summary}

The observations reported in this paper represent the first and, as yet, only opportunity to verify the parameterizations of turbulent scalar transfer used to diagnose ablation at the base of ice shelves in ocean circulation models. Based on this single observational dataset and our expectation of the level of complexity needed under more extreme thermal forcing, the best parameterization would appear to be a three-equation formulation of the form

$$
\rho_{i} a_{b} L_{i}=\rho_{i} c_{i} a_{b}\left(T_{i}-T_{b}\right)-\rho_{w} c_{w} u_{*} \Gamma_{T}\left(T_{b}-T_{w}\right),
$$

$\rho_{i} a_{b}\left(S_{b}-S_{i}\right)=-\rho_{w} u_{*} \Gamma_{S}\left(S_{b}-S_{w}\right)$,

and

$$
T_{b}=\lambda_{1} S_{b}+\lambda_{2}+\lambda_{3} P_{b}
$$

with turbulent transfer coefficients taken from Table 2. In Eq. (11) the heat conduction into the ice shelf (first term on the right-hand side) has been parameterized following Nøst and Foldvik (1994) and Holland and Jenkins (1999) because the basal temperature gradient within the ice shelf is unknown in a stand-alone ocean model. In coupled ice shelf-ocean models it would be preferable to retain the exact form in Eq. (1).

While a three-equation formulation is generally to be preferred, owing to its potentially wider applicability, it does produce a quadratic equation for the ablation rate. Linearization of this system could be an advantage in reduced or analytical models, in which case the twoequation formulation,

$$
\rho_{i} a_{b} L_{i}=\rho_{i} c_{i} a_{b}\left(T_{i}-T_{f}\right)-\rho_{w} c_{w} u_{*} \Gamma_{\{T S\}}\left(T_{f}-T_{w}\right)
$$


and

$$
T_{f}=\lambda_{1} S_{w}+\lambda_{2}+\lambda_{3} P_{b}
$$

with turbulent transfer coefficient taken from Table 2 is recommended. We reemphasize that use of this simpler formulation results in no degradation in the fit between calculated and observed ablation rates for our limited set of measurements.

In both cases the friction velocity is calculated as in Eq. (3) or (10), depending on the treatment of tidal currents, with the drag coefficient taken from Table 2. The drag coefficient is the parameter in Table 2 that is least well constrained by independent observational evidence. Adjustment of its value has therefore been the primary means of tuning the above equations to replicate the observations. Use of this value thus entails the implicit assumptions that the theory presented in section 2 is exact and that the turbulent transfer coefficients estimated for sea ice are appropriate for the base of an ice shelf. Temporal variability of the boundary layer and the differing nature of the boundary flow beneath ice shelves, where the forcing comes from buoyancy and tides, and beneath sea ice, where the primary forcing is the wind-driven drift of the ice cover, could violate these assumptions.

In the absence of further observations, the above equations represent the optimal choice for models of the ocean circulation beneath ice shelves. However, there can be little doubt that further observations could lead to significant improvements, particularly if those observations could sample a broad range of basal roughness characteristics, water temperatures, and tidal regimes. Direct measurements of turbulent fluxes through an evolving boundary layer are also crucial to ensure that parameter tuning is not used to compensate for theoretical deficiencies.

Acknowledgments. The authors are grateful to Miles McPhee, David Holland, and an anonymous reviewer for constructive comments on an earlier version of this paper.

\section{REFERENCES}

Beckmann, A., H. Hellmer, and R. Timmermann, 1999: A numerical model of the Weddell Sea: Large-scale circulation and water mass distribution. J. Geophys. Res., 104, 23 375-23 391.

Corr, H. F. J., A. Jenkins, K. W. Nicholls, and C. S. M. Doake, 2002: Precise measurement of changes in ice-shelf thickness by phase-sensitive radar to determine basal melt rates. Geophys. Res. Lett., 29, 1232, doi:10.1029/2001GL014618.

Determann, J., and R. Gerdes, 1994: Melting and freezing beneath ice shelves: Implications from a three-dimensional oceancirculation model. Ann. Glaciol., 20, 413-419.
Grosfeld, K., R. Gerdes, and J. Determann, 1997: Thermohaline circulation and interaction between ice shelf cavities and the adjacent open ocean. J. Geophys. Res., 102, 15 595-15 610.

Hellmer, H. H., and D. J. Olbers, 1989: A two-dimensional model for the thermohaline circulation under an ice shelf. Antarct. Sci., 1, 325-336.

Holland, D. M., and A. Jenkins, 1999: Modeling thermodynamic ice-ocean interactions at the base of an ice shelf. J. Phys. Oceanogr., 29, 1787-1800.

$\longrightarrow$, and - 2001: Adaptation of an isopycnic coordinate ocean model for the study of circulation beneath ice shelves. Mon. Wea. Rev., 129, 1905-1927.

, R. H. Thomas, B. de Young, M. H. Ribergaard, and B. Lyberth, 2008: Acceleration of Jakobshavn Isbræ triggered by warm subsurface ocean waters. Nat. Geosci., 1, 659-664, doi:10.1038/ngeo316.

Holland, P. R., and D. L. Feltham, 2006: The effects of rotation and ice shelf topography on frazil-laden ice shelf water plumes. J. Phys. Oceanogr., 36, 2312-2327.

- A. Jenkins, and D. M. Holland, 2008: The response of ice shelf basal melting to variations in ocean temperature. J. Climate, 21, 2558-2572.

Jacobs, S. S., H. H. Hellmer, and A. Jenkins, 1996: Antarctic ice sheet melting in the southeast Pacific. Geophys. Res. Lett., 23, 957-960.

Jenkins, A., 1991: A one-dimensional model of ice shelf-ocean interaction. J. Geophys. Res., 96, 20 671-20 677.

, and A. Bombosch, 1995: Modeling the effects of frazil ice crystals on the dynamics and thermodynamics of ice shelf water plumes. J. Geophys. Res., 100, 6967-6981.

, D. M. Holland, K. W. Nicholls, M. Schröder, and S. Østerhus, 2004: Seasonal ventilation of the cavity beneath Filchner-Ronne Ice Shelf simulated with an isopycnic coordinate ocean model. J. Geophys. Res., 109, C01024, doi:10.1029/2001JC001086.

- H. F. J. Corr, K. W. Nicholls, C. L. Stewart, and C. S. M. Doake, 2006: Interactions between ice and ocean observed with phase-sensitive radar near an Antarctic ice shelf grounding line. J. Glaciol., 52, 325-346.

Kader, B. A., and A. M. Yaglom, 1972: Heat and mass transfer laws for fully turbulent wall flows. Int. J. Heat Mass Transfer, 15, 2329-2351.

$\longrightarrow$, and — 1977: Turbulent heat and mass transfer from a wall with parallel roughness ridges. Int. J. Heat Mass Transfer, 20, 345-357.

Little, C. M., A. Gnanadesikan, and R. Hallberg, 2008: Large-scale oceanographic constraints on the distribution of melting and freezing under ice shelves. J. Phys. Oceanogr., 38, 2242-2255.

MacAyeal, D. R., 1984: Thermohaline circulation below the Ross Ice Shelf: A consequence of tidally induced vertical mixing and basal melting. J. Geophys. Res., 89, 597-606.

McPhee, M. G., 1990: Small-scale processes. Polar Oceanography. Part A: Physical Science, W. O. Smith Jr., Ed., Academic Press, 287-334.

- 1992: Turbulent heat flux in the upper ocean under sea ice. J. Geophys. Res., 97, 5365-5379.

_ 2008: Air-Ice-Ocean Interaction: Turbulent Ocean Boundary Layer Exchange Processes. Springer, 215 pp.

, G. A. Maykut, and J. H. Morison, 1987: Dynamics and thermodynamics of the ice/upper ocean system in the marginal ice zone of the Greenland Sea. J. Geophys. Res., 92, 7017-7031.

, C. Kottmeier, and J. H. Morison, 1999: Ocean heat flux in the central Weddell Sea during winter. J. Phys. Oceanogr., 29, 1166-1179. 
- J. H. Morison, and F. Nilsen, 2008: Revisiting heat and salt exchange at the ice-ocean interface: Ocean flux and modeling considerations. J. Geophys. Res., 113, C06014, doi:10.1029/ 2007JC004383.

Millero, F. J., 1978: Annex 6: Freezing point of seawater. Eighth report of the Joint Panel of Oceanographic Tables and Standards, UNESCO Marine Science Tech. Paper 28, 29-31.

Nicholls, K. W., 1996: Temperature variability beneath Ronne Ice Shelf, Antarctica, from thermistor cables. J. Geophys. Res., 101, 1199-1210.

—, and K. Makinson, 1998: Ocean circulation beneath the western Ronne Ice Shelf, as derived from in situ measurements of water currents and properties. Ocean, Ice, and Atmosphere: Interactions at the Antarctic Continental Margin, S. S. Jacobs and R. F. Weiss, Eds., Antarctic Research Series, Vol. 75, Amer. Geophys. Union, 301-318.

_ ——, and M. R. Johnson, 1997: New oceanographic data from beneath Ronne Ice Shelf, Antarctica. Geophys. Res. Lett., 24, $167-170$

, and Coauthors, 2006: Measurements beneath an Antarctic ice shelf using an autonomous underwater vehicle. Geophys. Res. Lett., 33, L08612, doi:10.1029/2006GL025998.
, S. Østerhus, K. Makinson, T. Gammelsrød, and E. Fahrbach, 2009: Ice-ocean processes over the continental shelf of the southern Weddell Sea, Antarctica: A review. Rev. Geophys., 47, RG3003, doi:10.1029/2007RG000250.

Nøst, O. A., and A. Foldvik, 1994: A model of ice shelf-ocean interaction with application to the Filchner-Ronne and Ross Ice Shelves. J. Geophys. Res., 99, 14 243-14 254.

Notz, D., M. G. McPhee, M. G. Worster, G. A. Maykut, K. H. Schlünzen, and H. Eicken, 2003: Impact of underwaterice evolution on Arctic summer sea ice. J. Geophys. Res., 108, 3223, doi:10.1029/2001JC001173.

Scheduikat, M., and D. J. Olbers, 1990: A one-dimensional mixed layer model beneath the Ross Ice Shelf with tidally induced vertical mixing. Antarct. Sci., 2, 29-42.

Schoof, C., 2007: Ice sheet grounding line dynamics: Steady states, stability and hysteresis. J. Geophys. Res., 112, F03S28, doi:10.1029/ 2006JF000664.

Smedsrud, L. H., and A. Jenkins, 2004: Frazil ice formation in an Ice Shelf Water plume. J. Geophys. Res., 109, C03025, doi:10.1029/2003JC001851.

Steele, M., G. L. Mellor, and M. G. McPhee, 1989: Role of the molecular sublayer in the melting or freezing of sea ice. J. Phys. Oceanogr., 19, 139-147. 